\title{
Analgesic effects of 5-alkyloxy-4-amino-2(5H)-furanones as cholecystokinin-2 antagonists
}

\author{
Eric Lattmann ${ }^{1}$, Jintana Sattayasai ${ }^{2}$, Carl H. Schwalbe ${ }^{1}$, Yodchai Boonprakob ${ }^{2}$ \\ Simon Dunn ${ }^{1}$, Feyisayo Fajana ${ }^{1}$ and Pornthip Lattmann ${ }^{1}$
}

1) The School of Pharmacy, Aston University, Aston Triangle, Birmingham B4 7ET, England

2) Department of Pharmacology, Faculty of Medicine, Khon Kaen University, 40002 Khon Kaen, Thailand

Correspondence:

Dr. Eric Lattmann, Medicinal Chemistry, The School of Pharmacy, Aston University, Aston Triangle, Birmingham B4 7ET, England; Tel: +44-(0) 121204 3980; Fax: +44-

(0) 121359 0733; e-mail: e.lattmann@aston.ac.uk

\section{Key words:}

CCK-antagonists, 2(5H) furanones, synthesis, radioligand binding, GPI, isolated tissue preparations, tail immersion test, analgesia potentiation.

\begin{abstract}
4-Amino-2(5H)-furanones were synthesized in high yields over 2 synthetic steps from readily available mucochloric acid. These 5-alkyloxy-4-amino-2(5H)-furanones were screened in a ${ }^{[125]} \mathrm{I}-\mathrm{CCK}-8$ radioligand receptor binding assay for $\mathrm{CCK}_{2}$ affinity and novel active ligands in the nanomolar range were identified. SAR was optimized leading to the cyclohexyl derivative 25 with an $\mathrm{IC}_{50}$ of $27 \mathrm{nM}$. Furanone 18 was obtained as a stable crystalline material with an $\mathrm{IC}_{50}$ of $85 \mathrm{nM}$, but occurred a higher $\mathrm{CCK}_{2}$ selectivity. It was subsequently tested in the isolated guinea pig ileum (GPI) assay with sulfated $\mathrm{CCK}_{8}$ and the $\mathrm{CCK}$ antagonizing properties of the ligand were confirmed. The $\mathrm{CCK}_{2}$ selective antagonist $\mathbf{1 8}$ was found to potentiate analgesia in the tail flick assay in mice, for the strong opiate morphine, the partial opiate agonist tramadol and the tricyclic antidepressant (TCA) desimipramine.
\end{abstract}




\section{Introduction}

Cholecystokinin acts as a neuromodulator as well as gut hormone and CCK-ligands, agonists as well as antagonists [1], have been extensively investigated as potential drug molecules [2]. CCK-antagonists were studied as growth inhibitors in certain forms of cancer [3], as anxiolytics [4], in the treatment of schizophrenia [5], satiety [6] and as anti-panic agents [7]. The most simplified agonist, the shortened CCK tetrapeptide, was found to induce panic in patients and these effects were blocked by CCK antagonists [8]. In addition to anxiety [9] and depression [10], the clinically most relevant therapeutic area for CCK antagonists is pain management.

Asperlicin (Figure 1) was the first non-peptidal CCK antagonist lead structure from nature and analogues thereof, were studies as CCK ligands [11]. Simplification of the lead structure by Merck led to Devazepide [12], a potent $\mathrm{CCK}_{1}$ selective cholecystokinin antagonist, containing a 1,4-benzodiazepine template and an indole moiety. A phase II trial of Devazepide, which was only published in form of a conference report [13] showed a significant enhancement of the effect of opiates in the treatment of chronic and severe pain and the CCK neuropeptide pathway was reviewed and a featured clinical application for pain [14].

The indolyl amide of devazepide was replaced by a urea linkage and this resulted in Merck's L-365,260, a $\mathrm{CCK}_{2}$ selective antagonist. Further SAR optimization led to Zeria's Z-360, in which the N- alkyl side chain and the 5- position (cyclohexyl-) was optimized for potency (Figure 1). Additionally, a meta-carboxylic acid on the aryl urea linkage was introduced to enhance water solubility of this most recent $\mathrm{CCK}_{2}$ antagonist [15] (Figure 1).

In our search for new CCK ligands, the 1,4-benzodiazepine template was varied by a combinatorial solid phase synthesis [16] and optimised in terms of CCK binding affinity [17]. The 1,4-benzodiazepine structure [18] was replaced by an achiral diphenyl pyrazolone template, giving novel CCK antagonists with an indole carboxylic acid [19] and a phenyl urea moiety [20] and they displayed excellent animal data on anxiety and depression [21].

Figure 1 
Again, having realized the poor pharmacokinetic properties these agents, a search for a completely novel, smaller template with a molecular weight $<350$, a log p about 3 and a polar surface area for membrane penetration of less that 100A, with no urea linkage was initiated.

This resulted in the discovery and SAR- optimization of 4-amino-2(5H)-furanones, which are reported here in this publication. For the first time now a totally novel, nonurea and non- benzodiazepine template [22] was available as potent $\mathrm{CCK}_{2}$ receptor antagonist. In vivo evaluation in mice using the tailflick test [23] was initiated with tramadol, morphine and finally desimipramine and resulted a relevant potentiation of analgesia.

\section{Results and discussion}

\subsection{Synthesis and SAR - optimisation}

Alkoxy-2(5H)-furanones were generally prepared from mucochloric acid using previously developed methods [24]. The overall starting material of this short chemical sequence is furfural, which is converted into mucochloric acid on an industrial scale, mainly for the use of this intermediate in plant protection and pharmaceuticals.

\section{Scheme 1.}

Propargylalcohol, allylalcohol, benzylalcohol and cyclohexyl methanol were reacted in presence of toluene under reflux using a Dean Stark trap (Method A). For the isopropyloxy-3,4-dichloro-2 $(5 \mathrm{H})$ furanone excess of the alcohol was applied (Method 2) and the intermediate was obtained in large crystals once crystalline.

The 5-alkoxy (5-propargyl-, allyl-, isopropyloxy-, benzyloxy, and cyclohexylmethyloxy-) 2(5H)-furanone intermediates were reacted at slightly elevated temperatures with an excess of the parent amine into the desired 4-amino-5 -alkoxy2(5H)-furanones 1-26.

The target molecules were obtained in a low yield for the propargyl- series and in good yields for the allyloxy, isopropyloxy and benzyloxy- series. Iso-propyloxy derivatives were generally inactive, but crystalline solids, while the benzyloxy series provided active and crystalline target molecules. Chemical stability is linked with crystalline 
properties via the melting point, explaining the desire of the medicinal chemist for white crystalline materials.

\section{SAR optimisation}

The propargyl series contained the original lead structure 1, which was identified, when the combinatorial library of antibacterial 4-amino-furanones was screened in a CCK radioligand binding assay. The 4-isobutyl lead structure 1, which was identified by chance, was obtained in a low yield and occurred as sticky brown oil and the optimization of structure activity relationships are outlined in Table 1.

The change of the butyl group in this series resulted generally in lower binding affinity and the benzyl derivative 2 was found of 2 fold lower and the $\mathrm{N}$-methyl benzyl analogue of a similar activity.

The introduction of piperazinyl-, morpholinyl- and other heterocyclic groups was found to result inactive molecules $\mathbf{4}$ and $\mathbf{5}$.

The isobutyl analogue 6 containing an allyloxy-group, was 5 times less potent and the closely related n-butyl derivative $\mathbf{8}$ was found 20 times less potent in the receptor binding assay.

Subsequently the 5-alkoxy C3 unit was varied and a series of isopropyloxy furanones 9-17 were prepared and tested and an unspecific micromolar activity was determined.

\section{Table 1}

The benzyl group is a classical bioisostere of the propargyl group and the benzyl analogue of the isobutyl furanone $\mathbf{1 8}$ was 3 times more potent than lead structure $\mathbf{1}$. It was also obtained in a good chemical yield as a white, crystalline material.

For n-butyl and for the secondary butyl 5-benzyloxy-furanones 19 and 20, the bioactivity was decreased.

The pyrazol derivative $\mathbf{2 1}$, as well as the cyclopropyl furanone $\mathbf{2 2}$ and the cyclopentyl derivative $\mathbf{2 3}$ were found of a high nanomolar binding affinity, while the cyclohexyl analogue $\mathbf{2 4}$ had a significantly lower activity.

For the 5-cyclohexyl methyl aminofuranones series, the methyl analogue $\mathbf{2 6}$ occurred no binding affinity up to 10 micromolar and the isobutyldrivative $\mathbf{2 5}$ was identified as the most potent derivative of the entire series. The replacement of the aromatic phenyl 
group by a cyclohexyl group resulted in enhanced binding affinity for the privileged isobutyl amino structure 25. A similar enhancement phenyl versus cyclohexyl was previously observed in Z-360, a recent $\mathrm{CCK}_{2}$ antagonist [25].

Figure 2.

Thus, overall 4 potent CCK ligands in the nanomolar range were identified. The furanone 18 occurred an $\mathrm{IC}_{50}$ of $85 \mathrm{nM}$ and displayed 30 times selectivity towards the $\mathrm{CCK}_{2}$ receptor. Furanone $\mathbf{2 1}$ and $\mathbf{2 3}$ displayed slightly lower binding affinities and are outlined in Figure 2.

The cyclohexyl derivative 25 showed an enhanced $\mathrm{IC}_{50}$ about $27 \mathrm{nM}$, but was less selective, only 10 times for the CCK2R. It was obtained as an oily solid, which makes purification under GMP conditions by recrystallization impossible.

The isobutyl-amino-benzyloxy-furanone $\mathbf{1 8}$ was recrystallized from methanol and the crystal structure was determined.

Figure 3.

The crystal structure of the high yield - high purity -compound, furanone 18, is outlined in Fig 3, supporting excellent manufactoring properties due to appropiate physical chemical properties. In the crystal structure, the 5-benzyloxy moiety is orientated below the furanone plain and the 4-amino substituent is located above.

In order to rationalise drug ligand interactions of furanonone 18 with the $\mathrm{CCK}_{2} /$ gastrin receptor, molecular modeling studies were performed.

In figure 4 the docking of the furanone $\mathbf{1 8}$ into the $\mathrm{CCK}_{2}$ receptor is outlined and key drug ligand interactions are analysed as followed:

Van der Waals interactions of the isobutyl group with Ala106 explain the importance of the 2 methyl groups of isobutyl, which both interact with the methyl side chain of alanin. Therefore, even minor modifications of the alkyl group resulted in less binding affinity.

Figure 4. 
The carbonyl oxygen of the ligand binds to Arg 106, while the O1 occurred hydrogen binding with the alpha $\mathrm{H}$ of $\operatorname{Trp} 105$.

The aromatic benzyl group interacts with a lipophilic pocket of the $\mathrm{CCK}_{2}$ receptor and in particular interactions with Ile122, explained an enhanced binding affinity for the cyclohexyl ring system of ligand furanone 25.

\section{Functional assay- isolated guinea pig ileum preparation}

In a radiolabelled binding assay with native brain and pancreatic membranes, potent and selective ligands were identified. The CCK ligands may act as antagonists, and this was investigated using isolated tissue preparations.

Figure 5

Sulfated $\mathrm{CCK}_{8}$ resulted in dose dependent contractions of the GPI, which are outlined in fig 5. From $1 \mathrm{nM}$ onwards a small response was obtained, which reached plateau about $100 \mathrm{nM}$ concentrations. 500nM final bath concentration of the test molecule $\mathbf{1 8}$ shifted the curve to the right and 1 micromolar concentration of the furanone 18 resulted in nearly a complete inhibition of $\mathrm{CCK}_{8 \mathrm{~s}}$ induced contractions, so that it is now confirmed, that the ligand furanone $\mathbf{1 8}$ acted as CCK antagonist.

The small alkyl amino-benzyloxyfuranone molecule 18 occurred a cLogP about 2.6 compared with a cLogP of Diazepam of 2.7. Therefore, a sufficient brain penetration should be anticipated, essential for CNS activity. A high percentage of preclinical candidates drop out due to a poor pharmacokinetic profile and in this is in particular complex for a neuromodulator.

$\mathrm{CCK}$ antagonists potentiate the analgesic effects of opiates and for this potent $\mathrm{CCK}_{2}$ antagonist 18 the scope of analgesia was investigated.

Tramadol is a partial opiate agonist and also NA/SE reuptake inhibitor. Here, for the first time the tricyclic antidepressant desipramine was included in the evaluation of one selected CCK antagonist, furanone 18.

\section{In vivo analgesic tests}




\section{In vivo assay - analgesia potentiation assay [26] in mice for furanone 18}

The effects of CCK on the modulation of pain transmission and the opioid effects are well established [27, 28], and typically a low dose of morphine or a high dose of a weak opiate agonist will results in a good potentiation of analgesia [29] in the tail immersion test [30].

Figure 6.

The furanone 18 was intraperitoneally injected as a first injection to build up a plasma concentration of the CCK antagonist and then, tramadol/morphine/desimipramine was subcutaneously injected and subsequently the analgesic effect was evaluated in the tail flick assay (Figure 6).

In all treated groups, no effect on nociception [29] for doses of up to $5 \mathrm{mg} / \mathrm{kg}$ was observed for the furanone $\mathbf{1 8}$ in the tail immersion test [30] as a single agent. Administered in conjunction with tramadol/morphine and desimipramine at $0.05 \mathrm{mg}$ $/ \mathrm{kg}$ showed no potentiation of analgesia and a clinically relevant significant effect was observed at $0.5 \mathrm{mg} / \mathrm{kg}$.

For tramadol $(20 \mathrm{mg} / \mathrm{kg})$ and concomitant administration of furanone $18(0.5 \mathrm{mg})$ the analgesic effect in the tailflick test is equivalent to a $2 \mathrm{mg} / \mathrm{kg}$ dose of morphine.

For morphine the potentiation of analgesia was also confirmed. Morphine analgesia is potentiated by a CCK antagonist and the $2 \mathrm{mg} / \mathrm{kg}$ morphine dose is, in presence of furanone 18 , equivalent to $8 \mathrm{mg} / \mathrm{kg}$ morphine, which is therapeutically relevant to reduce side effects of opiates.

Most interestingly, for desimipramine at $0.5 \mathrm{mg} / \mathrm{kg}$ a maximum possible effect of $6 \%$ was determined. Tricyclic antidepressants, TCA's, such as desimipramine, show clinically a useful analgesic effect in man and in mice this effect is very small $(0.3 \%$ MPE). Here, in presence of $0.5 \mathrm{mg} / \mathrm{kg}$ CCK antagonist 18 the $20 \mathrm{mg} / \mathrm{kg}$ desimipramine dose is equivalent to $20-40 \mathrm{mg}$ tramadol. Thus $0.5 \mathrm{mg} / \mathrm{kg}$ of furanone 18 potentiated the analgesic effect of a classical TCA by factor 20 .

The effects of CCK on the modulation of pain transmission and the opioid effects are well established $[27,28]$ and we have shown here, the useful adjunct therapy of these agents in pain management. Previously, it was shown, that the $\mathrm{CCK}_{2}$ antagonist CI-988 
potentiated the analgesia of morphine and clomipramine [31] and therefore, it may be concluded, that this represents a general therapeutic application of $\mathrm{CCK}_{2}$ antagonists. Trimipramine is in use as second line treatment for persistent neuropathic pain, which still represents an unmet medical need. CCK antagonists also block the development of morphine tolerance $[32,33]$ another further possible therapeutic feature in pain management.

\section{Conclusions}

Chemically, the bis-substituted amino-furanones are not related to previously known CCK antagonizing small organic molecules and they do not contain the widely used urea linkage. Our amino-furanones represent a totally novel "new chemical entity" for a CCK antagonist, a CNS drug like molecule and most preferred an adjunct in pain management.

The tail immersion test is a robust assay to evaluate analgesia of selected CCK ligands in combination with approved analgesics. A classical tissue preparation confirmed reliably the antagonism of the ligands. Overall a good in vitro in vivo correlation was found.

During scale up, the yield for the solid isobutyl derivative $\mathbf{1 8}$ was increased to $>70 \%$ over 2 steps, and this molecule is available in $>99.7 \%$ purity and was selected for preclinical development. The greater $\mathrm{CCK}_{2}$ selectivity of $\mathbf{1 8}$, compared with $\mathbf{2 5}$ may result in less toxicity due to less interference with the physiological role of cholecystokinin, mediated by $\mathrm{CCK}_{1}$ receptors.

\section{$4 \quad$ Materials and Methods}

\subsection{Synthesis}

The chemicals were obtained from Aldrich (Gillingham, UK) and Lancaster (Lancaster, UK). Atmospheric pressure chemical ionisation mass spectroscopy (APCI), negative or positive mode, was carried out using a Hewlett-Packard 5989b quadrupole instrument (Vienna, Austria). Proton and Carbon NMR spectra were obtained on a Bruker AC 250 instrument (Follanden, Switzerland), operating at $250 \mathrm{MHz}$, calibrated with the solvent reference peak or TMS. IR spectra were plotted from $\mathrm{KBr}$ discs on a Mattson 300 FTIR Spectrometer. Melting points were recorded from a Stuart Scientific (Coventry, UK) melting points and are uncorrected. 


\section{Preparation of 3,4-Dichloro-5-alkoxy-furan-2-(5H)-one building blocks}

Preparation of 3,4-Dichloro-5-propargyloxy-furan-2-(5H)-one A

Method A - Toluene-Dean-Stark

To a solution of (10 g, $0.06 \mathrm{~mol})$ mucochloric acid in toluene $(50 \mathrm{ml})$, propargyl alcohol ( 2 eq., $6.5 \mathrm{~g}, 0.12 \mathrm{~mol})$ and concentrated sulphuric acid $(0.2 \mathrm{ml})$ were added. The resulting solution was left for 2 days to reflux using Dean and Stark apparatus. The brown oily tar like crude product was analysed by TLC and then quenched with saturated sodium bicarbonate solution $(50 \mathrm{ml})$. After leaving the crude mixture to settle for 10 minutes, the product was extracted with ether $(3 \times 50 \mathrm{ml})$. The organic layers were combined and dried using magnesium sulphate. The solvent was removed in vacuum, resulting in a dark brown coloured oil.

Yield $=61 \% ;{ }^{1} \mathrm{H} \mathrm{NMR}\left(\mathrm{CDCl}_{3}\right) 250 \mathrm{MHz}: \delta=6.11(\mathrm{~s}, 1 \mathrm{H}), 4.58(\mathrm{~m}, 2 \mathrm{H}), 2.96(\mathrm{t}, J=$ $2.4 \mathrm{~Hz}, 1 \mathrm{H}) ;{ }^{13} \mathrm{C} \mathrm{NMR}\left(\mathrm{CDCl}_{3}\right) \delta=163.1,147.5,128.2,98.6,78.1,77.7,57.4 \mathrm{ppm}$; IR (KBr-disc) u max: 3578, 3293, 2938, 2881, 2122, 1799, 1634, 1450, 1355, 1232, $1143,1017,903,748,687 \mathrm{~cm}^{-1}$.

Preparation of 5-Allyloxy-3,4-dichloro-5H-furan-2-one B

Method A: To a solution of ( $10 \mathrm{~g}, 0.06 \mathrm{~mol})$ mucochloric acid in toluene $(50 \mathrm{ml})$, allyl alcohol (2 eq., $7.1 \mathrm{~g}, 0.12 \mathrm{~mol})$ and concentrated sulphuric acid $(0.2 \mathrm{ml})$ were added. The resulting solution was left for 2 days according to method A.

The crude furanone, which was obtained as dark brown coloured oil, was distilled under vacuum to give an orange liquid.

Yield $=69 \% ;{ }^{1} \mathrm{H} \mathrm{NMR}\left(\mathrm{CDCl}_{3}\right) 250 \mathrm{MHz}: \delta=5.99(\mathrm{~s}, 1 \mathrm{H}), 5.78(\mathrm{~m}, 1 \mathrm{H}), 5.27(\mathrm{~m}, 1 \mathrm{H})$, $5.48(\mathrm{~m}, 1 \mathrm{H}), 4.32(\mathrm{~m}, 2 \mathrm{H}) \mathrm{ppm} .{ }^{13} \mathrm{C} \mathrm{NMR}\left(\mathrm{CDCl}_{3}\right) \delta=163.3,147.9,131.9,124.2$, 119.5, 99.7, 71.1 ppm; IR (KBr-disc) u max: 3413, 3092, 2935, 2870, 2365, 2339, 1796, $1642,1334,1236,1157,1020,899,778,748 \mathrm{~cm}^{-1}$.

Preparation of 3,4-Dichloro-5-isopropoxy-5H-furan-2-one $\mathbf{C}$

Method B, (excess alcohol): To a solution of (10 g, $0.06 \mathrm{~mol})$ mucochloric acid in excess isopropanol $(60 \mathrm{ml})$, concentrated sulphuric acid $(0.2 \mathrm{ml})$ was added. The resulting solution was left for 2 days to reflux. The brown oily crude product was analysed by TLC and then quenched with saturated sodium bicarbonate solution (50 $\mathrm{ml}$ ). After leaving the crude mixture to settle for 10 minutes, the product was extracted 
with ether $(3 \times 50 \mathrm{ml})$. The organic layers were combined and dried using magnesium sulphate. The solvent was removed in vacuum, resulting in a light dark brown coloured oil, which was distilled under vacuum giving a colourless liquid.

Yield $=73 \% ;{ }^{1} \mathrm{H}$ NMR $\left(\mathrm{CDCl}_{3}\right) 250 \mathrm{MHz}: \delta=5.90(\mathrm{~s}, 1 \mathrm{H}), 4.25(\mathrm{~m}, 1 \mathrm{H}), 1.29+1.42$ $(\mathrm{d}, 6 \mathrm{H}) \mathrm{ppm} .{ }^{13} \mathrm{C} \mathrm{NMR}\left(\mathrm{CDCl}_{3}\right) 250 \mathrm{MHz}: \delta=163.7,148.0,123.9,100.3,75.1,22.6$, 22.0 ppm; IR (KBr-disc) U max: 3392, 2975, 2927, 1797, 1645, 1460, 1380, 1326, 1234 , $1160,1118,951,892,746 \mathrm{~cm}^{-1}$.

Preparation of 5-Benzyloxy-3,4-dichloro-5H-furan-2-one D

Method A: To a solution of (10 g, $0.06 \mathrm{~mol})$ mucochloric acid in toluene $(50 \mathrm{ml})$, benzyl alcohol (2 eq., $13.8 \mathrm{~g}, 0.12 \mathrm{~mol})$ and concentrated sulphuric acid $(0.2 \mathrm{ml})$ were added and reacted according to method A. The crude furanone, which was obtained as a light brown coloured oil, was distilled under vacuum giving a yellow liquid.

Yield $=77 \% ;{ }^{1} \mathrm{H}$ NMR $\left(\mathrm{CDCl}_{3}\right) 250 \mathrm{MHz}: \delta=7.48(\mathrm{~m}, 5 \mathrm{H}), 5.94(\mathrm{~s}, 1 \mathrm{H}), 4.88(\mathrm{~m}, 2 \mathrm{H})$ ppm; ${ }^{13} \mathrm{C} \mathrm{NMR}\left(\mathrm{CDCl}_{3}\right) 250 \mathrm{MHz}: \delta=163.3,147.7,135.2,128.9,128.5,126.2,124.5$, 99.7, 71.4 ppm; IR (KBr-disc) $\cup$ max: 3432, 3034, 2928, 2371, 2344, 1794, 1642, 1452 , $1330,1231,1148,1022,909,746,697 \mathrm{~cm}^{-1}$.

Preparation of 3,4-Dichloro-5-cyclohexylmethoxy-5H-furan-2-one $\mathbf{E}$

Method A: To a solution of $(10 \mathrm{~g}, 0.06 \mathrm{~mol})$ mucochloric acid in toluene $(50 \mathrm{ml})$, cyclohexyl methanol (2 eq. $13.5 \mathrm{~g}, 0.12 \mathrm{~mol})$ and concentrated sulphuric acid $(0.2 \mathrm{ml})$ were added and the reaction mixture was reacted according to method A. The crude furanone was distilled under vacuum to give an orange liquid.

Yield $=57 \% ;{ }^{1} \mathrm{H}$ NMR $\left(\mathrm{CDCl}_{3}\right) 250 \mathrm{MHz}: \delta=5.73(\mathrm{~s}, 1 \mathrm{H}), 3.90(\mathrm{~m}, 2 \mathrm{H}), 1.39-1.76$ $(\mathrm{m}, 11 \mathrm{H}) \mathrm{ppm} ;{ }^{13} \mathrm{C} \mathrm{NMR}\left(\mathrm{CDCl}_{3}\right) 250 \mathrm{MHz}: \delta=161.4,147.6,125.3,101.2$, 68.6, 40.3, 29.5, 26.7, 25.7 ppm; IR (KBr-disc) U max: 3334, 2926, 2851, 2669, 1794, 1732, 1634, $1444,1177,1018,729,697 \mathrm{~cm}^{-1}$.

\section{Preparation of 3-Chloro-4-substituted amino-5-alkyloxyloxy-5H-furan-2-ones}

General Method:

Building block (2 mmol A-E / 0.41, 0.42, 0.42, 0.52, 0.53g), was dissolved in DMF (2 $\mathrm{ml}$ ) and placed into $30 \mathrm{ml}$ glass vials. Amines $(5 \mathrm{mmol})$ were added carefully dropwise to each vial. The vials were placed in a heating block and heated to $45^{\circ} \mathrm{C}$ for 48 hours. 
The compound was extracted with ether $(10 \mathrm{ml})$ and washed twice with water $(10 \mathrm{ml})$. The organic layer was dried using anhydrous magnesium sulphate and removed in vacuum to give a dark brown oil, which was purified using column chromatography (solvent system: 50/50 ether/petrol ether) to give the desired product.

3-Chloro-4-isobutylamino-5-prop-2-ynyloxy-5H-furan-2-one 1

Yield $=12 \%$ brown oil; MW243.7; MS $(\mathrm{APCI}(+)): 244 / 246(\mathrm{M}+1) \mathrm{m} / \mathrm{z} ;{ }^{1} \mathrm{H}$ NMR $\left(\mathrm{CDCl}_{3}\right) 250 \mathrm{MHz}: \delta=5.92(\mathrm{~s}, 1 \mathrm{H}), 5.19(\mathrm{bs}, \mathrm{NH}), 4.41(\mathrm{~s}, 2 \mathrm{H}), 3.28(\mathrm{~m}, 2 \mathrm{H}), 2.55(\mathrm{~m}$, 1H), $1.84(\mathrm{~m}, 1 \mathrm{H}), 1.08(\mathrm{~m}, 6 \mathrm{H}) \mathrm{ppm} ;{ }^{13} \mathrm{C} \mathrm{NMR}\left(\mathrm{CDCl}_{3}\right) \delta=166.2(\mathrm{C}=\mathrm{O}), 155.3$, 104.5, 94.5, 76.7, 78.1, 56.1, 51.1, 29.6, 19.7 ppm; IR (KBr-disc) U max: 3306, 3103, 2967, 2937, 2881, 2370, 1748, 1646, 1542, 1458, 1434, 1335, 1126, 969, 747, $701 \mathrm{~cm}^{-}$ 1.

4-(benzylamino)-3-chloro-5-(prop-2-ynyloxy)furan-2(5H)-one 2

36\% brown oil; MW: 277.7; MS (APCI(+)): 278, $280(\mathrm{M}+1) \mathrm{m} / \mathrm{z} .{ }^{1} \mathrm{H}$ NMR $\left(\mathrm{CDCl}_{3}\right)$ 300K $\delta: ~ 7.36(\mathrm{~m}, 5 \mathrm{H}) ; 5.98(\mathrm{~s}, 1 \mathrm{H}), 5.20(\mathrm{~s}, \mathrm{NH}), 4.66(\mathrm{~s}, 2 \mathrm{H}), 4.45(\mathrm{~m}, 1 \mathrm{H}), 4.41(\mathrm{~m}$, 2H), 2.55( $\mathrm{m}, 1 \mathrm{H}), \mathrm{ppm} .{ }^{13} \mathrm{C} \mathrm{NMR}\left(\mathrm{CDCl}_{3}\right) \delta=168.1,155.8,135.6,129.0,128.6,126.3$, 108.3, 96.6, 78.2, 76.6, 54.9ppm. IR (KBr-disc) v max: 3380, 3283, 2358, 2338, 1752, $1646,1455,1326,1123,971 \& 695 \mathrm{~cm}^{-1}$.

4-(Benzyl-methyl-amino)-3-chloro-5-prop-2-ynyloxy-5H-furan-2-one 3 Yield = 49\%oily solid; MW: 291.7; MS (APCI(+)): 292/294 (M+1) m/z

${ }^{1} \mathrm{H} \mathrm{NMR}\left(\mathrm{CDCl}_{3}\right) 250 \mathrm{MHz}: \delta=7.16-7.41(\mathrm{~m}, 5 \mathrm{H}), 5.96(\mathrm{~s}, 1 \mathrm{H}), 4.70(\mathrm{~m}, 2 \mathrm{H}, 4.40(\mathrm{~m}$, $2 \mathrm{H}), 3.04(\mathrm{~s}, 3 \mathrm{H}), 2.48(\mathrm{~m}, 1 \mathrm{H}) \mathrm{ppm} ;{ }^{13} \mathrm{C} \mathrm{NMR}\left(\mathrm{CDCl}_{3}\right) \delta=168.2,155.6,135.7,129.0$, 128.6, 127.3, 107.3, 94.6, 78.1, 76.9, 55.9, 38.1 ppm. IR (KBr-disc) v max: 3441, 3296, 3037, 2930, 2374, 2343, 2128, 1766, 1643, 1460, 1419, 1353, 1270, 1229, 1116, 983, $747,703 \mathrm{~cm}^{-1}$.

4-(4-Benzyl-piperazin-1-yl)-3-chloro-5-prop-2-ynyloxy-5H-furan-2-one 4 Yield = 50\%; MP: $120-123{ }^{\circ} \mathrm{C} ; \mathrm{MW}: 346.8 ; \mathrm{MS}(\mathrm{APCI}(+)): 346 / 348(\mathrm{M}+1) \mathrm{m} / \mathrm{z}$ ${ }^{1} \mathrm{H} \mathrm{NMR}\left(\mathrm{CDCl}_{3}\right) 250 \mathrm{MHz}: \delta=7.18-7.38(\mathrm{~m}, 5 \mathrm{H}), 5.87(\mathrm{~s}, 1 \mathrm{H}), 4.36(\mathrm{~s}, 2 \mathrm{H}), 3.76(\mathrm{~m}$, $4 \mathrm{H}), 3.51(\mathrm{~s}, 2 \mathrm{H}), 2.42-2.39(\mathrm{~m}, 5 \mathrm{H}) \mathrm{ppm} .{ }^{13} \mathrm{C} \mathrm{NMR}\left(\mathrm{CDCl}_{3}\right) 250 \mathrm{MHz}: \delta=168.1$, 154.0, 137.2, 129.2, 128.4, 127.5, 103.0, 94.3, 76.9 76.8, 62.7, 55.7, 52.7, 47.5 ppm. 
IR (KBr-disc) U max: 3253, 2935, 2815, 2126, 1758, 1446, 1347, 1277, 1111, 985 , $849,740,693 \mathrm{~cm}^{-1}$.

3-Chloro-4-(2,6-dimethyl-morpholin-4-yl)-5-prop-2-ynyloxy-5H-furan-2-one 5

Yield = 47\%; Oily Solid; MW: 285.7; MS (APCI(+)): 286/288 (M+1) m/z; ${ }^{1} \mathrm{H}$ NMR $\left(\mathrm{CDCl}_{3}\right) 250 \mathrm{MHz}: \delta=5.94(\mathrm{~s}, 1 \mathrm{H}), 4.36(\mathrm{~s}, 2 \mathrm{H}), 3.89-4.25(\mathrm{~m}, 2 \mathrm{H}), 3.58-3.85(\mathrm{~m}, 2 \mathrm{H})$, 2.51-2.98 (m, 3H), $1.46(\mathrm{~m}, 6 \mathrm{H}) \mathrm{ppm} .{ }^{13} \mathrm{C} \mathrm{NMR}\left(\mathrm{CDCl}_{3}\right): \delta=170.4,153.7,104.2,94.3$, 77.8, 77.6, 66.0, 55.8, 52.6, 18.5, 18.4 ppm. IR (KBr-disc) v max: 3484, 3255, 2981, 2928, 2883, 2366, 2108, 1743, 1639, 1267, 1083, 981, 751, $697 \mathrm{~cm}^{-1}$.

5-Allyloxy-3-chloro-4-isobutylamino-5H-furan-2-one 6

Yield = 62\%; Oily Solid; MW: 245.7; MS (APCI(+)): 188/190 (M+), 246/248 (M+1) m/z; ${ }^{1} \mathrm{H}$ NMR $\left(\mathrm{CDCl}_{3}\right) 250 \mathrm{MHz}: \delta=5.89(\mathrm{~m}, 1 \mathrm{H}), 5.73(\mathrm{~s}, 1 \mathrm{H}), 5.34(\mathrm{~m}, 2 \mathrm{H}), 4.79$ (bs, NH), 4.27 (m, 2H), 3.22 (bs, 2H), $1.83(\mathrm{~m}, 1 \mathrm{H}), 1.16-0.98(\mathrm{~m}, 6 \mathrm{H}) \mathrm{ppm} ;{ }^{13} \mathrm{C} \mathrm{NMR}$ $\left(\mathrm{CDCl}_{3}\right): \delta=172.1,156.7,132.2,119.6,108.0,95.9,69.3$, 51.0, 29.6, 19.7 ppm; IR (KBr-disc) ט max: 3296, 3088, 2978, 2978, 2939, 2881, 1753, 1649, 1546, 1467, 1338, $1150,972,709 \mathrm{~cm}^{-1}$.

5-Allyloxy-4-sec-butylamino-3-chloro-5H-furan-2-one 7 Yield = 49\%; Oily Solid; MW: 245.7; MS (APCI(+)): 190/192 (M+), 246/248 (M+1) m/z; ${ }^{1} \mathrm{H}$ NMR $\left(\mathrm{CDCl}_{3}\right) 250 \mathrm{MHz}: \delta=5.89(\mathrm{~m}, 1 \mathrm{H}), 5.74(\mathrm{~s}, 1 \mathrm{H}), 5.28(\mathrm{~m}, 2 \mathrm{H}), 4.27$ $(\mathrm{m}, 2 \mathrm{H}), 1.68(\mathrm{~m}, 2 \mathrm{H}), 1.82(\mathrm{~m}, 3 \mathrm{H}), 0.99(\mathrm{t}, J=4.6 \mathrm{~Hz}, 3 \mathrm{H}) \mathrm{ppm} ;{ }^{13} \mathrm{C} \mathrm{NMR}\left(\mathrm{CDCl}_{3}\right)$ : $\delta=168.3,153.5,132.5,119.0,106.3,96.5,69.6,49.6,30.5,21.4,10.3$ ppm. IR (KBrdisc) U max: 3296, 3088, 2978, 2978, 2939, 2881, 1753, 1649, 1546, 1467, 1338, 1150 , $972,709 \mathrm{~cm}^{-1}$.

\section{5-Allyloxy-4-butylamino-3-chloro-5H-furan-2-one 8}

Yield = 57\%; Oily Solid; MW: 245.7(APCI(+)): 188/190 (M+), 246/248 (M+1) m/z ${ }^{1} \mathrm{H}$ NMR $\left(\mathrm{CDCl}_{3}\right) 250 \mathrm{MHz}: \delta=5.90(\mathrm{~m}, 1 \mathrm{H}), 5.76(\mathrm{~s}, \mathrm{CH}), 5.32(\mathrm{~m}, 2 \mathrm{H}), 4.29(\mathrm{~m}, 2 \mathrm{H})$, 3.43(bs, 2H), $1.63(\mathrm{~m}, 2 \mathrm{H}), 1.38(\mathrm{~m}, 2 \mathrm{H}), 0.98(\mathrm{t}, J=8.2 \mathrm{~Hz}, 3 \mathrm{H}) \mathrm{ppm} .{ }^{13} \mathrm{C} \mathrm{NMR}$ $\left(\mathrm{CDCl}_{3}\right) \delta=165.9,151.3,132.4,119.4,105.6,96.2,69.6,43.6,32.7,19.7,13.7 \mathrm{ppm}$. 
IR (KBr-disc) $\cup$ max: 3332, 3095, 2974, 2941, 2892, 1754, 1655, 1540, 1457, 1333, $1227,1138,1087,969,748,700 \mathrm{~cm}^{-1}$.

5-Benzyloxy-3-chloro-4-isobutylamino-5H-furan-2-one 18

Yield = 76\%; MP: 105-107 ${ }^{\circ} \mathrm{C} ;$ MW: 295.8; MS (APCI(+)): 188/190 (M+), 296/298 $(\mathrm{M}+1) \mathrm{m} / \mathrm{z} ;{ }^{1} \mathrm{H} \mathrm{NMR}\left(\mathrm{CDCl}_{3}\right) 250 \mathrm{MHz}: \delta=7.01-7.49(\mathrm{~m}, 5 \mathrm{H}), 5.79(\mathrm{~s}, \mathrm{CH}), 5.10(\mathrm{bs}$, $\mathrm{NH}), 4.71(\mathrm{bs}, 2 \mathrm{H}), 3.22(\mathrm{~m}, 2 \mathrm{H}), 1.79(\mathrm{~m}, 1 \mathrm{H}), 0.97(\mathrm{~m}, 6 \mathrm{H}) \mathrm{ppm} ;{ }^{13} \mathrm{C} \mathrm{NMR}\left(\mathrm{CDCl}_{3}\right)$ : $\delta=170.4,170.4,135.4,128.8,106.3,95.6,70.4,51.0,29.5,19.7 \mathrm{ppm}$.

IR (KBr-disc) ט max: 3460, 3252, 2977, 2937, 2877, 2368, 2341, 1741, 1631, 1433, $1353,1329,1255,1128,1028,961,750,703 \mathrm{~cm}^{-1}$.

$\begin{array}{ll}\mathrm{C}_{15} \mathrm{H}_{18} \mathrm{ClNO}_{3} & \mathrm{~V}=1529.9(9) \AA^{3} \\ \mathrm{M}_{\mathrm{r}}=295.75 & \mathrm{Z}=4 \\ \mathrm{~T}=293(2) \mathrm{K} & \mathrm{D}_{\mathrm{x}}=1.284 \mathrm{Mg} / \mathrm{m}^{-3} \\ \text { Tabular } & \mathrm{D}_{\mathrm{m}} \text { not measured } \\ 0.20 \times 0.15 \times 0.05 \mathrm{~mm} & \mathrm{R}\left[\mathrm{F}^{2}>2 \sigma\left(\mathrm{F}^{2}\right)\right]=0.0791 \\ \text { Colourless } & \text { wR }\left(\mathrm{F}^{2}\right)=0.1845 \\ \text { Mo Ko radiation: } \lambda=0.71073 \AA & 3207 \text { reflections } \\ \text { Monoclinic } & 187 \text { parameters } \\ \mathrm{P} 2{ }_{1} / \mathrm{c} & \\ \mathrm{a}=11.420(5) \AA & \\ \mathrm{b}=10.736(2) \AA & \\ \mathrm{c}=12.798(5) \AA & \\ \beta=102.83(4){ }^{\circ} & \end{array}$

Selected geometric parameters $\left(\AA{ }^{\circ}{ }^{\circ}\right)$

$\begin{array}{llll}\mathrm{Cl}(7)-\mathrm{C}(2) & 1.707(7) & \mathrm{O}(12)-\mathrm{C}(4) & 1.386(7) \\ \mathrm{O}(5)-\mathrm{C}(1) & 1.365(8) & \mathrm{C}(3)-\mathrm{N}(8) & 1.331(7) \\ \mathrm{O}(5)-\mathrm{C}(4) & 1.432(7) & \mathrm{C}(2)-\mathrm{C}(3) & 1.354(9) \\ \mathrm{O}(6)-\mathrm{C}(1) & 1.202(7) & & \\ & & & \\ \mathrm{C}(4)-\mathrm{O}(12)-\mathrm{C}(13) & 113.7(5) & \mathrm{O}(6)-\mathrm{C}(1)-\mathrm{O}(5) & 120.3(5) \\ \mathrm{O}(12)-\mathrm{C}(13)-\mathrm{C}(14) & 108.2(6) & \mathrm{C}(1)-\mathrm{C}(2)-\mathrm{Cl}(7) & 122.9(5) \\ \mathrm{N}(8)-\mathrm{C}(3)-\mathrm{C}(4) & 124.5(6) & \mathrm{C}(3)-\mathrm{C}(2)-\mathrm{Cl}(7) & 127.0(5) \\ \mathrm{O}(12)-\mathrm{C}(4)-\mathrm{O}(5) & 111.5(5) & \mathrm{C}(3)-\mathrm{N}(8)-\mathrm{C}(9) & 124.5(6)\end{array}$

5-Benzyloxy-4-butylamino-3-chloro-5H-furan-2-one 19

Yield = 68\%; MP: 109-112 ${ }^{\circ} \mathrm{C}$; MW: 295.8; MS (APCI(+)): 188/190 (M+), 296/298 $(\mathrm{M}+1) \mathrm{m} / \mathrm{z} ;{ }^{1} \mathrm{H} \mathrm{NMR}\left(\mathrm{CDCl}_{3}\right) 250 \mathrm{MHz}: \delta=7.39(\mathrm{~m}, 5 \mathrm{H}), 5.74(\mathrm{~s}, 1 \mathrm{H}), 4.64(\mathrm{~m}, 3 \mathrm{H})$, 
$3.31(\mathrm{bs}, 2 \mathrm{H}), 1.569(\mathrm{~m}, 2 \mathrm{H}), 1.39(\mathrm{~m}, 2 \mathrm{H}), 0.89(\mathrm{t}, \quad J=6.6 \mathrm{~Hz}, 3 \mathrm{H}) \mathrm{ppm} .{ }^{13} \mathrm{C} \mathrm{NMR}$ $\left(\mathrm{CDCl}_{3}\right) \delta=171.4,153.4,135.5,128.8,128.1,124.5,107.5,95.5,70.3,43.7,29.5$ , 19.7, 13.7 ppm; IR (KBr-disc) v max: 3419, 2067, 3028, 2928, 2371, 2338, 1794, $1642,1502,1456,1327,1234,1144,1022,972,902,750,707 \mathrm{~cm}^{-1}$.

5-Benzyloxy-4-sec-butylamino-3-chloro-5H-furan-2-one 20

Yield = 64\%; MP: $93-96{ }^{\circ} \mathrm{C} ; \mathrm{MW}: 295.8 ;$ MS (APCI(+)): 188/190 (M+), 296/298 $(\mathrm{M}+1) \mathrm{m} / \mathrm{z} ;{ }^{1} \mathrm{H} \mathrm{NMR}\left(\mathrm{CDCl}_{3}\right) 250 \mathrm{MHz}: \delta=7.30(\mathrm{~m}, 5 \mathrm{H}), 5.73(\mathrm{~s}, 1 \mathrm{H}), 5.11(\mathrm{bs}, \mathrm{NH})$, $4.68(\mathrm{~m}, 2 \mathrm{H}), 4.40$ (bs, NH), 3.49(bs, 1H), 1.46 (m, 2H), $1.16(\mathrm{~m}, 3 \mathrm{H}), 0.84(\mathrm{~m}, 3 \mathrm{H})$ ppm; ${ }^{13} \mathrm{C} \mathrm{NMR}\left(\mathrm{CDCl}_{3}\right) \delta=169.3,155.5,135.6,128.9,128.7,124.3,105.9,95.7,70.2$, 51.1, 30.5, 21.6, 21.6 ppm; IR (KBr-disc) ט max: 3272, 3085, 2977, 2929, 2880, 2368, $1732,1632,1560,1454,1348,1231,1123,966,749,700 \mathrm{~cm}^{-1}$.

5-Benzyloxy-3-chloro-4-(3-methyl-pyrazol-1-yl)-5H-furan-2-one 21

Yield =76\%; MP: 89-91 ${ }^{\circ} \mathrm{C}$; MW: 304.7; MS (APCI(+)): 305/307 (M+1) m/z; ${ }^{1} \mathrm{H} \mathrm{NMR}$ $\left(\mathrm{CDCl}_{3}\right) 250 \mathrm{MHz}: \delta=8.25(\mathrm{~m}, 1 \mathrm{H}), 7.31(\mathrm{~m}, 5 \mathrm{H}), 6.49(\mathrm{~s}, 1 \mathrm{H}) 6.40(\mathrm{~m}, 1 \mathrm{H}), 4.94(\mathrm{~m}$, 2H), $2.41(\mathrm{~s}, 3 \mathrm{H}) \mathrm{ppm} .{ }^{13} \mathrm{C} \mathrm{NMR}\left(\mathrm{CDCl}_{3}\right): \delta=165.7,153.7,147.3,135.5$ 130.9, 128.7, 128.6, 128.55, 111.3, 102.7, 99.1, 72.6, 13.7 ppm; IR (KBr-disc) v max: 3440, 3176, 2950, 2941, 2885, 2362, 2336, 1790, 1674, 1551, 1443, 1324, 1264, 1122, 1016, 983, $735,695 \mathrm{~cm}^{-1}$.

5-Benzyloxy-3-chloro-4-cyclopropylamino-5H-furan-2-one 22

Yield = 81\%; MP: $104-107^{\circ} \mathrm{C}$; MW: 279.7; MS (APCI(+)): 278/280 (M+) m/z

${ }^{1} \mathrm{H}$ NMR $\left(\mathrm{CDCl}_{3}\right) 250 \mathrm{MHz}: \delta=7.80(\mathrm{~m}, 5 \mathrm{H}), 5.95(\mathrm{~s}, 1 \mathrm{H}), 4.84(\mathrm{~m}, 3 \mathrm{H}), 2.99(\mathrm{~m}, 1 \mathrm{H})$, $0.79(\mathrm{~m}, 7 \mathrm{H}) \mathrm{ppm} ;{ }^{13} \mathrm{C} \mathrm{NMR}\left(\mathrm{CDCl}_{3}\right) \delta=161.4,153.4,133.6,128.8,128.7,126.4$, 106.1, 95.7, 70.8, 25.5, 18.3 ppm; IR (KBr-disc) v max: 3453, 3265, 3071, 2935, 2864, 2366, 1788, 1742 1636, 1442, 1348, 1245, 983, 753, $701 \mathrm{~cm}^{-1}$.

5-Benzyloxy-3-chloro-4-cyclopentylamino-5H-furan-2-one 23

Yield $=78 \%$; MP: $101-103{ }^{\circ} \mathrm{C}$; MW: 307.8 ;MS (APCI(+)): 284/286 (M+), 306/308 $(\mathrm{M}+1) \mathrm{m} / \mathrm{z} ;{ }^{1} \mathrm{H} \mathrm{NMR}\left(\mathrm{CDCl}_{3}\right) 250 \mathrm{MHz}: \delta=7.49(\mathrm{~m}, 5 \mathrm{H}), 5.78(\mathrm{~s}, 1 \mathrm{H}), 4.78(\mathrm{~m}, 2 \mathrm{H})$, 
4.01(bs, $\mathrm{NH}), 1.33-2.15\left(\mathrm{~m}, 8 \mathrm{H} \mathrm{ppm} ;{ }^{13} \mathrm{C} \mathrm{NMR}\left(\mathrm{CDCl}_{3}\right) \delta=165.2,151.3,135.5,128.8\right.$, 128.2 124.6, 104.2 , 95.6, 70.2, 55.3, 34.6, 23.7 ppm; IR (KBr-disc) v max: 3459, 3306, 3070, 2961, 2859, 2367, 2342, 1735, 1626, 1547, 1352, 1231, 1144, 1007, 959, 758, $707 \mathrm{~cm}^{-1}$.

5-Benzyloxy-3-chloro-4-cyclohexylamino-5H-furan-2-one 24

Yield = 49\%; Oily Solid; MW: 321.8; MS (APCI(+)): 322/324 (M+) m/z; ${ }^{1} \mathrm{H}$ NMR $\left(\mathrm{CDCl}_{3}\right) 250 \mathrm{MHz}: \delta=7.30(\mathrm{~m}, 5 \mathrm{H}), 5.78(\mathrm{~s}, 1 \mathrm{H}), 4.96(\mathrm{bs}, \mathrm{NH}), 4.76(\mathrm{~m}, 2 \mathrm{H}), 1.04-$ $2.18(\mathrm{~m}, 10 \mathrm{H}) \mathrm{ppm} ;{ }^{13} \mathrm{C} \mathrm{NMR}\left(\mathrm{CDCl}_{3}\right) \delta=167.5,155.5,135.5,128.7,128.4,124.2$, 104.5, 95.6, 67.0, 52.7, 34.5, 25.5, 25.1 ppm; IR (KBr-disc) v max: 3293, 3067, 2941, $2861,2375,2355,1754,1648,1550,1446,1337,1231,1134,1091,955,746,700 \mathrm{~cm}^{-}$ 1.

3-Chloro-5-cyclohexylmethoxy-4-isobutylamino-5H-furan-2-one 25

Yield $=59 \%$; MP: 119-122 ${ }^{\circ} \mathrm{C}$; MW: 301.8; MS (APCI(+)): 206/208 (M+), 302/304 $(\mathrm{M}+1) \mathrm{m} / \mathrm{z} ;{ }^{1} \mathrm{H} \mathrm{NMR}\left(\mathrm{CDCl}_{3}\right) 250 \mathrm{MHz}: \delta=5.75(\mathrm{~s}, 1 \mathrm{H}), 4.89(\mathrm{bs}, \mathrm{NH}), 3.53(\mathrm{~m}, 1 \mathrm{H})$, 3.49 (m, 1H), 3.37 (bs, 2H), 2.76 (bs, 1H), 1.53-1.79 (m, 5H), 0.81-1.42 (m, 12H) ppm; ${ }^{13} \mathrm{C} \mathrm{NMR}\left(\mathrm{CDCl}_{3}\right) \delta=165.5,153.6,104.2,97.0,74.0,51.1$, 37.7 , 29.8, 29.7, 27.0, 25.7, 19.74, 19.71ppm; IR (KBr-disc) v max: 3285, 2971, 2933, 2863, 2370, 1745, $1678,1630,1470,1333,1256,1147,1025,948,750,718 \mathrm{~cm}^{-1}$.

3-Chloro-5-cyclohexylmethoxy-4-methylamino-5H-furan-2-one 26

Yield $=55 \%$; MP: $117-120{ }^{\circ} \mathrm{C}$; MW: 259.7; MS (APCI(+)): 164/166 (M+1), 260/262 $(\mathrm{M}+) \mathrm{m} / \mathrm{z} ;{ }^{1} \mathrm{H} \mathrm{NMR}\left(\mathrm{CDCl}_{3}\right) 250 \mathrm{MHz}: \delta=5.72(\mathrm{~s}, 1 \mathrm{H}), 4.89(\mathrm{bs}, \mathrm{NH}), 3.49(\mathrm{~m}, 1 \mathrm{H})$, $3.37(\mathrm{~m}, 1 \mathrm{H}), 3.23(\mathrm{~m}, 3 \mathrm{H}), 2.76(\mathrm{bs}, 1 \mathrm{H}), 1.72(\mathrm{~m}, 5 \mathrm{H}), 0.77-1.39(\mathrm{~m}, 6 \mathrm{H}) \mathrm{ppm} ;{ }^{13} \mathrm{C}$ $\operatorname{NMR}\left(\mathrm{CDCl}_{3}\right) \delta=164.1,151.3,102.6$, 97.0, 74.2, 37.7, 30.6, 29.7, 27.0, 25.7 ppm. IR (KBr-disc) v max: 3267, 2925, 2848, 2370, 2338, 1742, 1684, 1632, 1451, 1329, 1255 , $1159,1016,949,755,716 \mathrm{~cm}^{-1}$. 


\subsection{Pharmacology}

\section{Cholecystokinin binding assay, ${ }^{[125]}$ I-CCK-8 receptor binding assay}

$\mathrm{CCK}_{1}$ and $\mathrm{CCK}_{2}$ receptor binding assays were performed, by using guinea pig cerebral cortex $\left(\mathrm{CCK}_{2}\right)$ or rat pancreas $\left(\mathrm{CCK}_{1}\right)$. Male guinea pig brain tissues were prepared according to the modified method described by Saita et al [34]. Pancreatic membranes were prepared as described by Charpentier et al [35].

Tissues were homogenized in ice cold sucrose $(0.32 \mathrm{M}, 25 \mathrm{ml})$ for 15 strokes at 500 rpm and centrifuged at $13000 \mathrm{rpm}$ for 10 minutes. The supernatant was re-centrifuged at $13000 \mathrm{rpm}$ for 20 minutes. The resulting pellet was re-dispersed to the required volume of buffer at $500 \mathrm{rpm}$ and stored in aliquots at $70^{\circ} \mathrm{C}$.

Binding was achieved using radioligand ${ }^{125}$ I-Bolton-Hunter labelled CCK, NEN at 25 pM. The samples were incubated with membranes $(0.1 \mathrm{mg} / \mathrm{ml})$ in $20 \mathrm{mM}$ Hepes, $1 \mathrm{mM}$ EGTA, $5 \mathrm{mM} \mathrm{MgCl}_{2}, 150 \mathrm{mM} \mathrm{NaCl}$, at $\mathrm{pH} 6.5$ for $2 \mathrm{hrs}$ at RT and then centrifuged at $11000 \mathrm{rpm}$ for 5 minutes. The membrane pellets were washed twice with water and the bound radioactivity was measured in a Packard Cobra counter.

\section{Isolated tissue preparation}

Adult male guinea pigs, weighing 200-250 g, were used and from the abdomen of the animals, the ileum was carefully excised at a site $15 \mathrm{~cm}$ away from the ileocaecal junction and washed with physiological solution. The mesentery of the ileum was removed and the ileal lumen was gently flushed with tyrode's solution to clear luminal contents. The prepared isolated tissue was rapidly incubated in Tyrode's solution maintained at $37^{\circ} \mathrm{C}$ and gassed with $95 \% \mathrm{O}_{2} / 5 \% \mathrm{CO}_{2}$.

Tyrode's solution of the following quantity was freshly prepared daily $(\mathrm{g} / \mathrm{l}): \mathrm{NaCl}, 8.0$; $\mathrm{KCl}, 0.2 ; \mathrm{CaCl}_{2}, 0.2 ; \mathrm{MgSO}_{4}, 0.1 ; \mathrm{NaH}_{2} \mathrm{PO}_{4}, 0.05 ; \mathrm{NaHCO}_{3}, 1.0 ;$ Glucose, 1.0. Stock solutions of test compounds were prepared weekly, diluted to required concentration as required and stored at a temp of $4^{\circ} \mathrm{C}$.

From the isolated tissue preparation, ileal strips of appropriate length were mounted vertically in organ bath containing tyrode's solution, under a tension of $1 \mathrm{~g}$ and allowed to equilibrate for 30 minutes. One end of the strip was attached to the hook at the bottom of the organ bath and the other end connected by a thread to the external isometric force transducer. During equilibration, tension was continuously adjusted to $1 \mathrm{~g}$ when 
required and the Tyrode's solution in the organ bath was changed every 20 minutes. All spontaneous contractions of longitudinal muscles were recorded with the aid of an isometric transducer linked to a power lab chart computer unit.

\section{Effects on CCK-8 stimulated isolated guinea pig ileum}

To study the effect of furanone $\mathbf{1 8}$ on strips prepared from guinea pig ileum, $\mathrm{CCK}_{8 \mathrm{~S}}$ was dissolved in distilled water to prepare a stock solution of $500 \mu \mathrm{M}$ solution, from which cumulative additions of increasing concentrations $(0.1 \mathrm{nM}, 1 \mathrm{nM}, 5 \mathrm{nM}, 10 \mathrm{nM}$, $20 \mathrm{nM}, 30 \mathrm{nM}$, and $40 \mathrm{nM}$ ) were tested to plot a dose response curve. Test compounds and Lorglumide/L365,260 as standard were added to the organ bath 10 minutes before exposure to the next $\mathrm{CCK}_{8 \mathrm{~S}}$ serial concentrations.

\section{Animal studies}

Experiments were conducted in male standard IRC mice obtained from the animal house, Faculty of Medicine, Khon Kaen University. Each experimental group consisted of 6 animals and the treatment procedures were approved by the ethical committee, Faculty of Medicine, Khon Kaen University (BEA030699).

Mice were intraperitoneal injected with either test compound dissolved in 5\% DMSO at the volume not more than $0.2 \mathrm{ml} / \mathrm{animal}$. At $30 \mathrm{~min}$ after treatment, animals were tested as described in the following sections.

\section{Nociception test}

The tail immersion test: The thermal response latency was measured by the tail immersion test. The animals were placed into individual restraining cages leaving the tail hanging freely. The tail was immersed into water preset at $50^{\circ} \mathrm{C}$. The response time, at which the animal reacted by withdrawing its tail from water, was recorded and the cut-off time was $10 \mathrm{sec}$ in order to avoid damaging the animal's tissue. The base line withdrawal thresholds (BT) were recorded prior to the first injection. Test thresholds (TT) were measured $60 \mathrm{~min}$ after the second injection. The test thresholds were expressed as a percentage of Maximal Possible Effect (\% MPE) using the equation:

$$
\% \mathrm{MPE}=\{(\mathrm{TT}-\mathrm{BT}) /(45-\mathrm{BT})\} \times 100
$$


DMSO (5\%), furanone (in $5 \%$ DMSO) was intraperitoneally injected as the first injection. Twenty min after the first, the second injection was done by subcutaneously injected with tramadol at either 10,20 or $40 \mathrm{mg} / \mathrm{kg}$ body weight.

\section{Molecular modeling}

For target preparation the protein structures, pdb identifier $1 \mathrm{HZN}$ for the $\mathrm{CCK}_{1}$ and 1L4T for the $\mathrm{CCK}_{2}$-gastrin receptor were downloaded from the protein data bank (www.rcs.org) and docking was performed using Autodock Vina and Hex. After several docking trials for the $\mathrm{CCK}_{2}$ receptor the results were analysed and visualized using Chimera and Designer studio 4.5. After visual inspection and scores, results were presented to understand drug ligand interaction with the $\mathrm{CCK}_{2}$ receptor.

\section{Statistical methods}

The data were expressed as mean \pm SD and one-way analysis of variance (ANOVA) and supplementary Tukey test for pairwise comparison were tested to determine for any significant difference at $\mathrm{p}<0.05$.

\section{Acknowledgement}

We deeply appreciate assistance of Wanchai Airarat in the animal experiments and we are grateful for funding from PNB Vesper life Sciences PVT. No conflict of interest is declared.

\section{References}

[1] I. M. McDonald, Exp. Opin. Ther. Patents. 2001, 11, 445-462.

[2] M. G. Bock, R. M. DiPardo, E. C. Mellin, N. C. Newto, J. Med. Chem. 1994, 37, 722-724.

[3] E. Lattmann, P. Arayarat, KKU. Sci. J. 2003, 31, 178-193.

[4] C. T. Dourish, S. Ravard, Trends Pharmacol. Sci. 1990, 11, 271-273.

[5] K. Rasmussen, J.F. Czachura, M. E. Stockton, J. J. Howbert, J. Pharmacol. Exp. Ther. 1993, 264, 480-488.

[6] C. T. Dourish, W. Rycroft, S. D. Iversen, Science 1989, 245, 1509-1511.

[7] B. K. Trivedi, Curr. Med. Chem. 1994, 1, 313-327.

[8] J. Bradwejn, D. Koszycki, G. Meterissian, Can. J. Psychiatry 1990, 35, 83-85. 
[9] E. Lattmann, J. Sattayasai, P. Lattmann, D. C. Billington, C. H. Schwalbe, J. Boonprakob, W. Airarat, H. Singh, M. Offel M, Drug Discov. Ther. 2007, 1, 45-56.

[10] E. Lattmann, Y. Boonprakob, J. Sattayasai, Drug Discov. Ther. 2008, 2, 344352.

[11] E. Lattmann, D. C. Billington, D. R. Poyner, S. B. Howitt, M. Offel, Drug Des. Discov. 2001, 17, 219-230.

[12] B. E. Evans, K. E. Rittle, M. G. Bock, R. M. DiPardo, R. M. Freidinger, W. L. Whitter, G. F. Lundell, D. F. Veber, P. S. Anderson, R. S. Chang, D. J. Cerino, J. Med. Chem. 1988, $31,2235-2246$.

[13] K. Simpson, M. Serpell, T. D. McCubbins, N. L. Padfield, N. Edwards, K. Markam, D. Eastwood, R. Block, D. J. Rowbotham, Management of neuropathic pain in patients using a CCK antagonist Devazepide as an adjunct to strong opioids, $4^{\text {th }}$ International conference on the mechanisms and treatment of neuropatic pain, Sep. 2001, San Francisco, USA.

[14] J. Hughes, G. N. Woodruff, Arzneim.-Forsch. / Drug Res. 1992, 42, 250-255.

[15] A. M. Grabowska, T. M. Morris, A. J. McKenzie, R. Kumari, H. Hamano, Y.

Emori, K. Yoshinaga, S .A. Watson, Regul. Peptides 2008, 146, 46-57.

[16] E. Lattmann, D. C. Billington, D. R. Poyner, P. Arayarat, S. B. Howitt, S. Lawrence, M. Offel, Drug Des. Discov. 2002, 18, 9-21.

[17] E. Lattmann, J. Sattayasai, D. C. Billington, D. R. Poyner, P. Puapairoj, S. Tiamkao, W. Airarat, H. Singh, M. Offel, J. Pharm. Pharm. 2002, 54, 827-834.

[18] M. Offel, P. Lattmann, H. Singh, D. C. Billington, Y. Bunprakob, J. Sattayasai, E. Lattmann, Archiv der Pharmazie / Chemistry in Life Science 2006, 339, 163-173.

[19] E. Lattmann, H. Singh, J. Boonprakob, P. Lattmann, J. Sattayasai, J. Pharm. Pharm. 2006, $58,1-9$.

[20] E. Lattmann, J. Sattayasai, J. Boonprakob, P. Lattmann, H. Singh, Arzneim.-Forsch. / Drug Research 2005, 55, 251-258.

[21] E. Lattmann, J. Sattayasai, Y. Boonprakob, H. Singh, P. Lattmann, S. Dunn, Drug Discov. Ther. 2008, 2, 156-167.

[22] E. Lattmann, P. Lattmann, J. Boonprakob, W. Airarat, H. Singh, M. Offel, J. Sattayasai, Arzneim.-Forsch. / Drug Research 2009, 59, 61-71.

[23] Y. Yu, A. Jawa, W. Pan, A. J. Kastin, Peptides 2004, 25, 2257-2289.

[24] E. Lattmann, N. Sattayasai, C. H. Schwalbe, S. Niamsanit, D. C. Billington, P. Lattmann, C. A. Langley, H. Singh, S. Dunn, Curr. Drug Discov. Technol. 2006, 3, 125-134. 
[25] K. Yoshinaga, T. Horii, H. Hamano, R. Eta, T. Ozaki, Y. Orikawa, K. Yoshii, Y.

Kawabata, Y. Hori, K. Seto, M. Takei, Y. Kuraishi, Biol. Pharm. Bull. 2010, 33, 244-248.

[26] H. G. Vogel, W. H. Vogel (Ed.), Drug Discovery and Evaluation: Pharmacological assays, Springer, Berlin, 1997, 232.

[27] M. F. O’Neill, C. T. Dourish, S. D. Iversen, NeuroPharmacol. 1989, 28, 243-247.

[28] M. F. O’Neill, C. T. Dourish, S. D. Iversen, Eur. J. Pharmacol. 1990, 193, 203-208.

[29] J. M. Walker, W. C. Dixon, Physiol. Behav. 1983, 30, 481-483.

[30] A. Cowan in Modern methods in pharmacology Volume 6: Testing and

Evaluation of Drugs of Abuse (Ed. M. W. Adler, A. Cowan), Wiley-Liss Inc., New

York, 1990, Recent approaches in the testing of analgesics in animals, 33.

[31] M. A. Coudoré-Civiale, C. Courteix, M. Boucher, M. Méen, J. Fialip, A.

Eschalier, D. Ardid, Neurosci. Lett. 2000, 286, 37-40.

[32] C. T. Dourish, M. F. O’Neill, J. Coughlan, S. J. Kitchener, D. Hawley, S. D.

Iverson, Eur. J. Pharmacol. 1990, 176, 35-44.

[33] C. T. Dourish, M. F. O’Neill, L. W. Schaffer, P. K. Siegi, S. D. Iversen, J.

Pharmacol. Exp. Ther. 1990, 255, 1158-1165.

[34] Y. Saita, H. Yazawa, Y. Honma, A. Nishida, K. Miyata, K. Honda, Eur. J.

Pharmacol. 1994, 269, 249-281.

[35] B. Charpentier, D. Pelaprat, C. Durieux, A. Dor, M. Reibaud, J. C. Blanchard, B.

P. Roques, Proc. Natl. Acad. Sci. U S A. 1988, 85, 1968-1973. 
<smiles>CC(C)C[C@H]1N[C@@H]2N(C1=O)c1ccccc1[C@@]2(O)CC1NC(=O)c2ccccc2-n2c1nc1ccccc1c2=O</smiles>

Asperlicin<smiles>Cc1cccc(NC(=O)N[C@@H]2N=C(c3ccccc3)c3ccccc3N(C)C2=O)c1</smiles>

L-365,260<smiles>CN1C(=O)C(NC(=O)c2cc3ccccc3[nH]2)N=C(c2ccccc2)c2ccccc21</smiles>

Devazepide

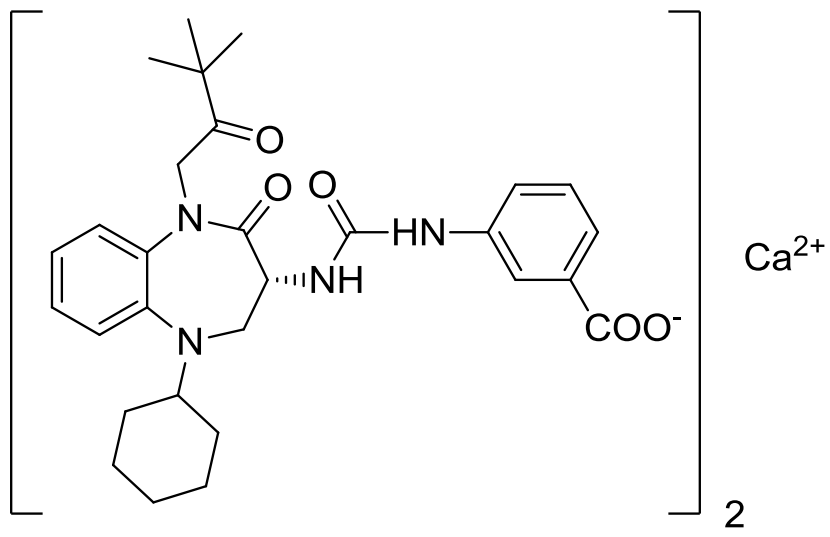

Z-360

Figure 1. Drug design from Asperlicin, an isolated natural product, via Devazepide, a $\mathrm{CCK}_{1}$ selective antagonist, to a $\mathrm{CCK}_{2}$ selective urea based antagonist, L-365,260. Drug optimisation from L-365,260 towards Z-360, a CCK 2 antagonist with improved potency and water solubility. 
Mucochloric acid<smiles>O=C1OC(O)C(Cl)=C1Cl</smiles><smiles>C=C=C</smiles>

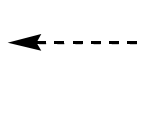<smiles>O=Cc1ccco1</smiles>

Furfural
Method A

Method B<smiles>[R]OC1OC(=O)C(Cl)=C1Cl</smiles>

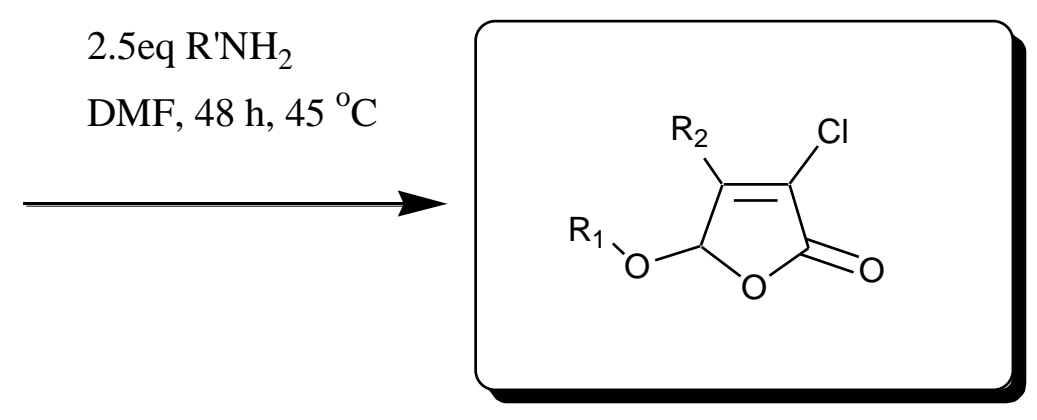

$1-26$

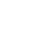

Furanone - building block A-E

$$
\text { R1= Propargyl-, allyl-, i-Prop-, benzyl-, cyclohexylmethyl- }
$$

Scheme 1. See experimental section for furanone - building blocks. Synthetic route for the formation of 5-alkoxy-4-aminofuran-2(5H)-ones 1-26. 


\begin{tabular}{|c|c|c|c|c|}
\hline Entry & $\mathrm{R} 1=$ & $\mathrm{R} 2=$ & CCK-B & CCK-A \\
\hline 1 & Propargyl- & Isobutylamino- & $220 \pm 29$ & $>10000$ \\
\hline 2 & Propargyl- & Benzylamino- & $470 \pm 34$ & - \\
\hline 3 & Propargyl- & N-methyl-benzylamino- & $280 \pm 32$ & - \\
\hline 4 & Propargyl- & Benzylpiperazinyl- & $>10000$ & - \\
\hline 5 & Propargyl- & 3,5-dimethylmorpholino- & $>10000$ & - \\
\hline 6 & Allyl- & Isobutylamino- & $1239 \pm 103$ & - \\
\hline 7 & Allyl- & Sec butylamino- & $>10000$ & - \\
\hline 8 & Allyl- & n-butylamino- & $4312 \pm 242$ & - \\
\hline 9 & Isopropyl- & Isopropylamino- & 1200 & - \\
\hline 10 & Isopropyl- & Cyclopropylamino- & 4300 & - \\
\hline 11 & Isopropyl- & Cyclopentylamino- & 5700 & - \\
\hline 12 & Isopropyl- & Cyclohexylamino- & 2300 & - \\
\hline 13 & Isopropyl- & Phenylethylamino- & 6700 & - \\
\hline 14 & Isopropyl- & Benzylamino- & 1300 & - \\
\hline 15 & Isopropyl- & N-methyl-benzylamino- & 2700 & - \\
\hline 16 & Isopropyl- & Dimethylanilino- & $2600 \pm 120$ & - \\
\hline 17 & Isopropyl- & Indolino- & 5400 & - \\
\hline 18 & Benzyl- & Isobutylamino- & $85 \pm 11$ & $2566 \pm 343$ \\
\hline 19 & Benzyl- & n-butylamino- & $548 \pm 43$ & - \\
\hline 20 & Benzyl- & Sec butylamino- & $627 \pm 43$ & - \\
\hline 21 & Benzyl- & 3-methylpyrazolo- & $162 \pm 13$ & $2344 \pm 321$ \\
\hline 22 & Benzyl- & Cyclopropylamino- & $263 \pm 18$ & $>10000$ \\
\hline 23 & Benzyl- & Cyclopentylamino- & $180 \pm 33$ & $2598 \pm 436$ \\
\hline 24 & Benzyl- & Cyclohexylamino- & $503 \pm 48$ & - \\
\hline 25 & Cyclohexylmethyl- & Isobutylamino- & $27 \pm 6$ & $260 \pm 21$ \\
\hline 26 & Cyclohexylmethyl- & Methylamino- & $>10000$ & - \\
\hline
\end{tabular}

Table 1. SAR optimisation with respect to receptor binding affinity for 4-amino-5alkoxy-furan-2(5H)-ones 1-26. $\mathrm{IC}_{50}$ in $\mathrm{nM} . \mathrm{N}=3$. 

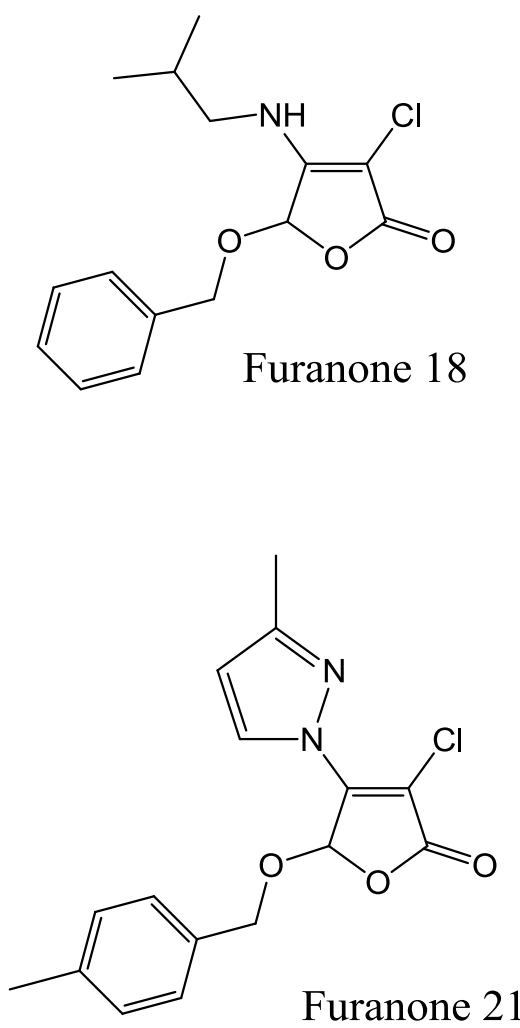
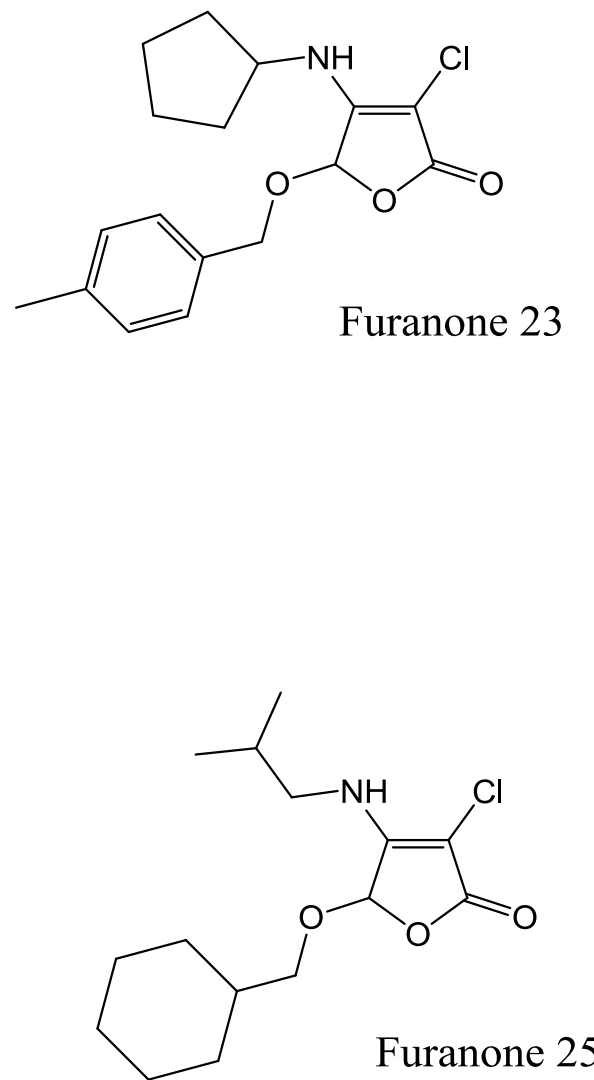

Figure 2. Overview of nanomolar $\mathrm{CCK}_{2}$ ligands. 


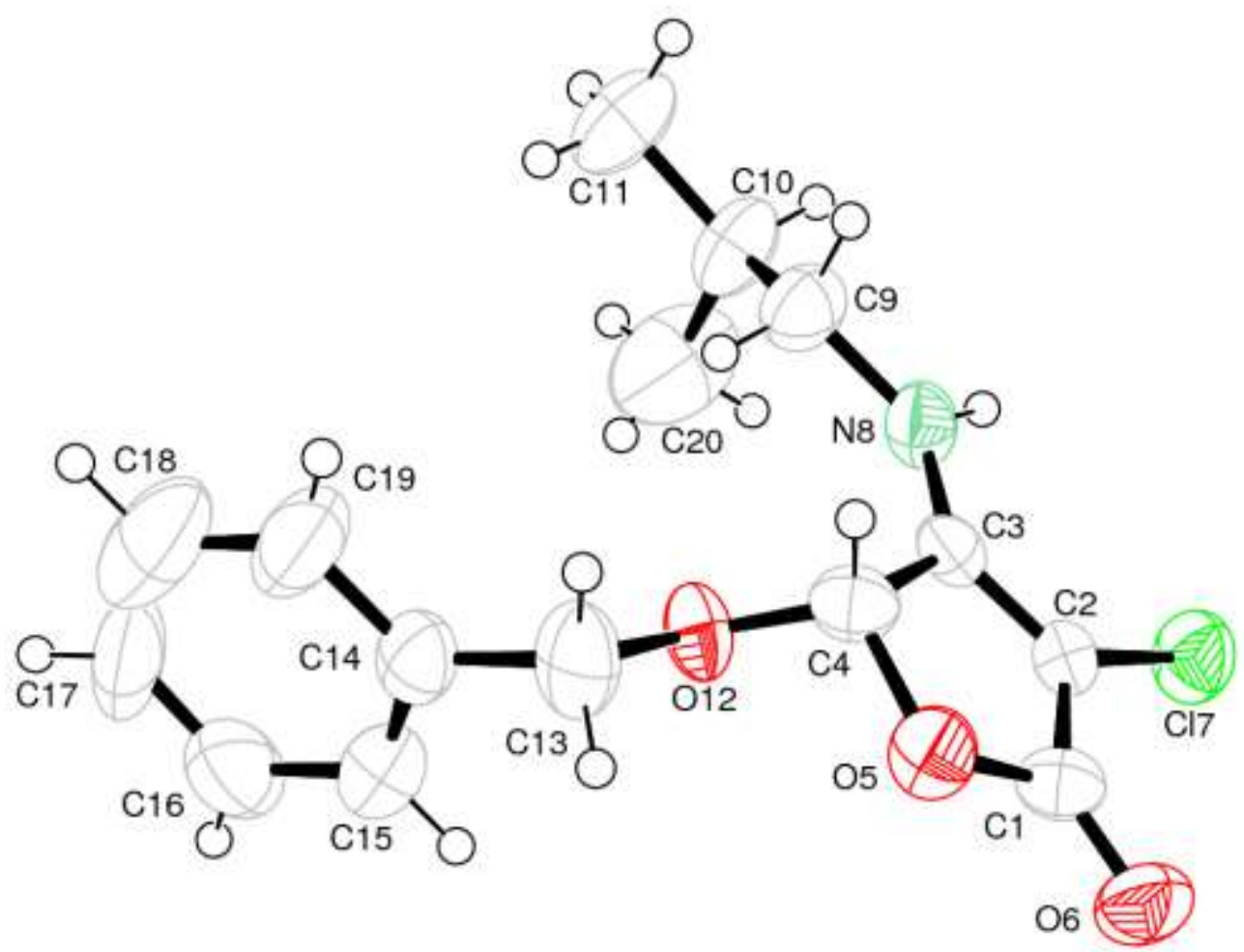

Figure 3. Crystal structure of 5-Benzyloxy-3-chloro-4-isobutylamino-5H-furan-2-one 18, sample recrystallised from methanol. 


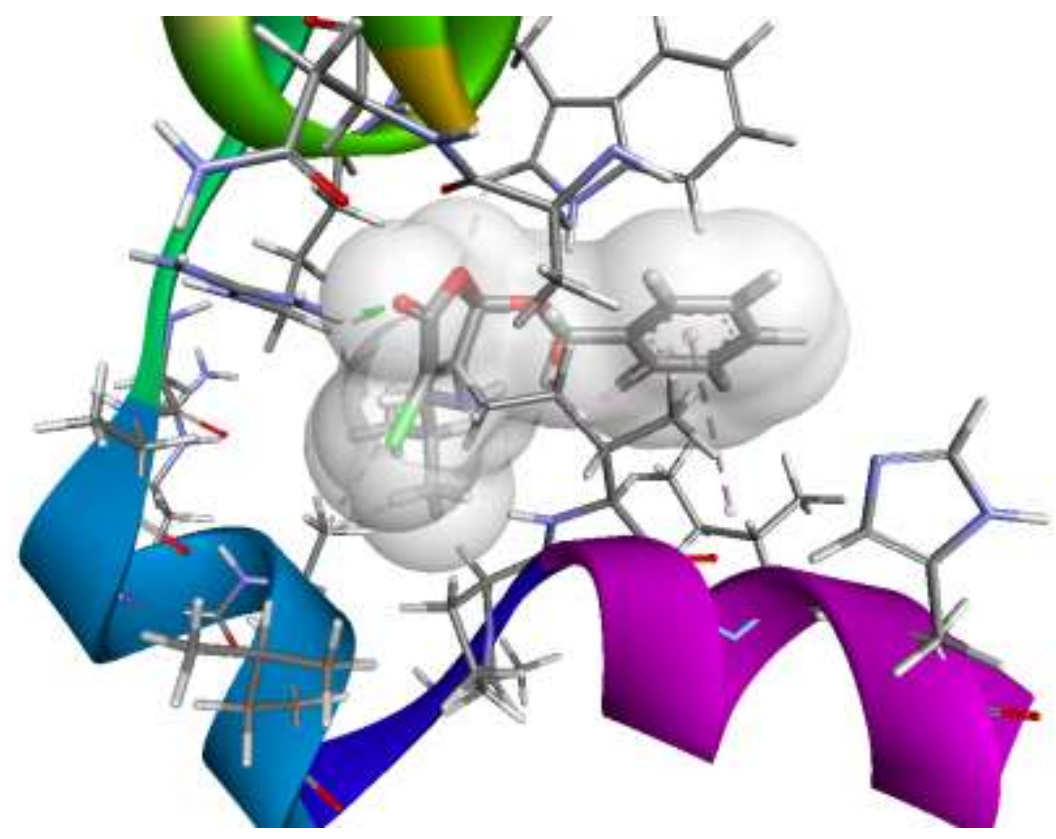

Figure 4. Docking of the furanone $\mathbf{1 8}$ into the active site of the $\mathrm{CCK}_{2}$ receptor. 


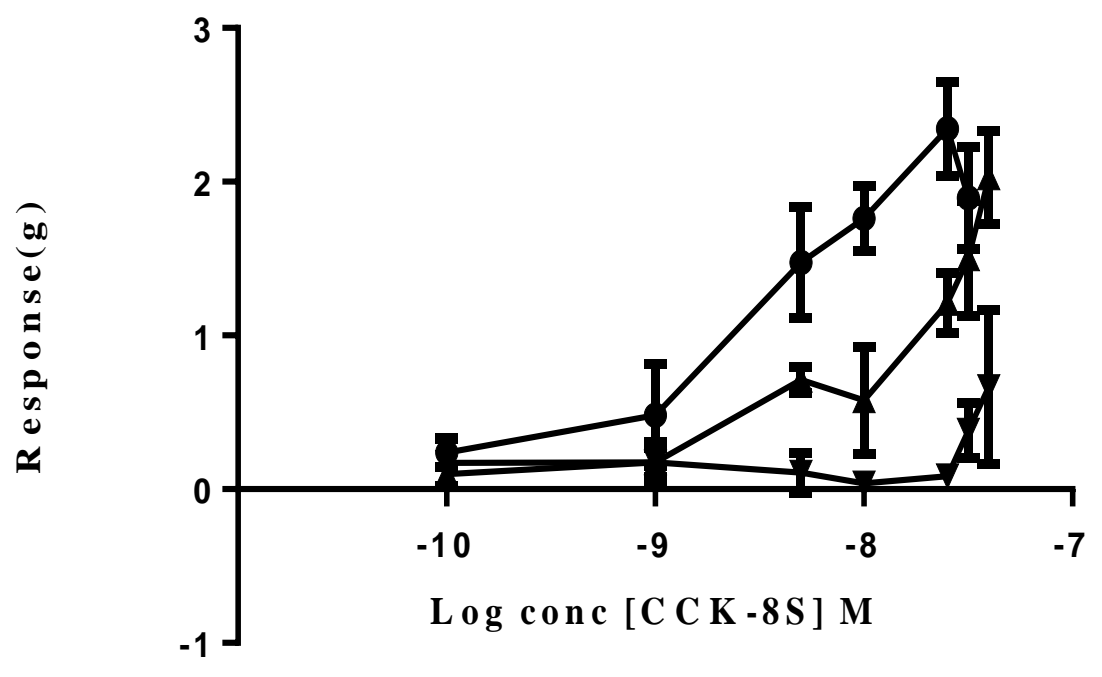

Figure 5. Isolated GPI. Cummulative log concentration response curves to $\mathrm{CCK}_{8 \mathrm{~s}}$ only $(\bullet)$ and $\mathrm{CCK}_{8 \mathrm{~S}}$ in the presence of $18: 0.5 \mu \mathrm{M}(\mathbf{\Delta}), 1.0 \mu \mathrm{M}(\boldsymbol{\nabla})$ on the guinea pig ileum, expressed as change of tension in $\mathrm{g}$. Each point represents the mean and the standard errors obtained from three different experiments. 


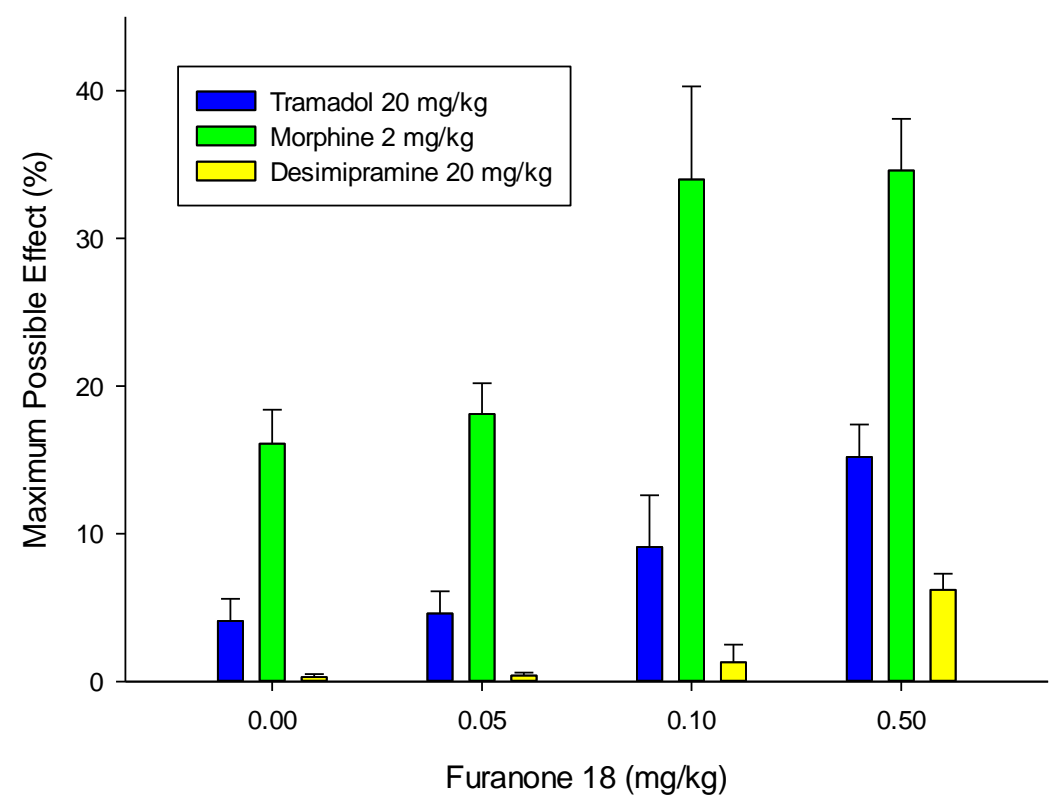

Figure 6. Maximum possible effect (MPE) of 3 doses of furanone 18 in the tail flick test in mice in \% MPE for tramadol-, morphine- and desimipramine potentiation. 